\title{
Effects of strength and neuromuscular training on functional performance in athletes after partial medial meniscectomy
}

\author{
Xiaohui Zhang ${ }^{\dagger}$, Min Hu${ }^{\dagger}$, Zhen Lou, Bagen Liao* \\ Department of Sport Medicine, Guangzhou Sport University, Guangzhou, China
}

The aims of this study were to determine an effective knee function rehabilitation program for athletes undergoing partial medial meniscectomy. Participants were randomly assigned to neuromuscular training (NT) or strength training (ST) group and subjected to functional assessments before surgery and again at 4 , and 8 weeks post hoc. Functional knee assessment, such as Lysholm knee scoring, star excursion balance, and BTE PrimusRS isokinetic performance tests were evaluated in each group. All postoperational symptoms were significantly improved after 4 and 8 weeks of NT and ST. Both NT and ST programs showed effective knee function recovery seen as an increase in muscular strength and endurance. However, the NT program showed the most significant functional improvement of dynamic balance and coordination.

Keywords: Strength training, Neuromuscular training, Athlete, Postmeniscectomy, Functional performance

\section{INTRODUCTION}

Meniscal lesions are common sports-related injuries in which surgical arthroscopic techniques can be used to repair the torn or injured meniscus. However, load, force, and contact stress on the knee joint significantly increase after meniscectomy and can induce composition changes of the articular cartilage that can lead to degeneration of the menisci and gradual development of osteoarthritis (OA) (Griffin et al., 2000; Matthews and St-Pierre, 1996).

Neuromuscular training (NT) has been shown to effectively strengthen the lower limb muscles, by achieving an optimal alignment of the trunk and lower limbs (Hall et al., 2015; Hunt et al., 2006).

Recent studies suggest that an early application of controllable stress training on the knee joint can improve function following meniscectomy (Brindle et al., 2001; Ortiz et al., 2010). The objective of rehabilitation in young athletes is a successful return to participation in high-level competitive sports, which requires a complete understanding of various rehabilitation training program (Ageberg et al., 2010; Bennell et al., 2011).

Rehabilitation of the athlete after meniscal surgery procedures can benefit from NT by improving the quality of knee joint cartilage, functional performance of the knee, and thereby reducing the symptoms of injury (Ericsson et al., 2006; Roos and Dahlberg, 2005). NT consists of exercises that focus on balance, perturbation, agility, stretch contraction i.e., plyometrics, strength, and endurance (Hübscher et al., 2010; Zech et al., 2009).

In this study, athletes who underwent partial meniscectomy were subjected to ST and NT programs in order to promote functional performance recovery and draw comparisons between the effects of ST and NT programs on athletic ability. Here we provide an adequate theoretical framework that can be used as reference for athletic rehabilitation training after knee surgery.
${ }^{*}$ Corresponding author: Bagen Liao (D) http://orcid.org/0000-0003-0371-5485 Department of Sports Medicine, Guangzhou Sports University, Guangzhou Avenue 1268, Guangzhou, China

Tel: +86-20-38024171, Fax: +86-20-38024171, E-mail: bagen2015@163.com

'These authors contributed equally to this study and should be considered co-first authors.

Received: August 30, 2016 / Accepted: January 1, 2017
This is an Open Access article distributed under the terms of the Creative Commons Attribution Non-Commercial License (http://creativecommons.org/licenses/by-nc/4.0/) which permits unrestricted non-commercial use, distribution, and reproduction in any medium, provided the original work is properly cited. 


\section{MATERIALS AND METHODS}

\section{Subject selection}

Thirty athletes between $18-35$ years (22 males and 8 females) who received arthroscopic partial medial meniscectomy from January 2015 to December 2015 were enrolled in this study which conducted in training facility of the laboratory, comprising of 15 cases of left knee injury and 15 cases of right knee injury (Table 1). After obtaining their informed consent, subjects were randomly assigned to two groups in a cross-matched manner to receive either NT or strength training (ST), depicted as the NT group and the ST group, respectively.

The exclusion criteria were as follows: previous rehabilitation training, anterior/posterior cruciate ligament injury grade II and above; knee joint fracture or dislocation; presence of osteochondritis dissecans in the knee joint; severe OA or traumatic arthritis; and/or existence of rheumatic or metabolic diseases.

The general clinical data of the two groups were compared by statistical analysis and any of the differences observed were not statistically significant $(P>0.05)$, indicating that the two groups of athletes were comparable.

This study followed the Declaration of Helsinki on medical protocol and ethics, and was approved by the regional Ethical Committee. All participants gave written informed consent before their participation.

\section{Rehabilitation training plan}

After medical discharge, the athletes enrolled in this study underwent adaptive rehabilitation training for one week to recover the flexibility of the joint and reduce further swelling. The training program started at the beginning of the second week and consisted of three sessions per week of at least $50 \mathrm{~min}$ for a total of 8 weeks. Muscle strengthening is an integral part of rehabilitation programs and has been previously demonstrated compellingly to

Table 1. Subjects recruited in the study

\begin{tabular}{lcc}
\hline Variable & ST group $(\mathrm{n}=15)$ & NT group $(\mathrm{n}=15)$ \\
\hline Gender & & $11: 4$ \\
$\quad$ Male:female & $11: 4$ & $23.16 \pm 3.45$ \\
Age $(\mathrm{yr})$ & $23.25 \pm 3.52$ & $77.53 \pm 5.71$ \\
Body weight $(\mathrm{kg})$ & $78.32 \pm 5.32$ & $178.85 \pm 3.19$ \\
Height $(\mathrm{cm})$ & $179.14 \pm 2.23$ & $92.08 \pm 1.56$ \\
Total leg length $(\mathrm{cm})$ & $91.35 \pm 2.42$ & $5.45 \pm 2.78$ \\
Years of training & $5.36 \pm 3.65$ & \\
\hline
\end{tabular}

Values are presented as mean \pm standard error.

ST, strength training; NT, neuromuscular training. be crucial for recovery after arthroscopic meniscectomy procedures (Goodwin and Morrissey, 2003; Koutras et al., 2012).

The NT program method used in this study has been previously reported as a biomechanical method (Abdominal-crunches; Lunge; Incomplete circle; Get tapping; kNee bends) aimed to improve sensory motor function and skeletal muscle strength of the lower limbs in athletes (Ageberg et al., 2010; Bennell et al., 2011). In addition, a number of studies have also suggested that early moderate exercise after meniscectomy may reduce the loading pressure on the medial knee joint, improve the quality of the cartilage, and reduce the risk factors of future OA development (Ericsson et al., 2009; Roos and Dahlberg, 2005; Thorstensson et al., 2007). In brief, details of the training programs for each group are as follows: (a) postoperative week 1 for ST group: athletes in this group performed exercises for $30 \mathrm{~min}, 7$ days per week to maintain and restore muscle strength and joint flexibility, such as ankle pumps, quadriceps isometric contraction, and straight leg raises. Weeks 2-4: training exercises were carried out for $50 \mathrm{~min}$ at least 5 times per week incorporating sandbags or elastic bands in resistance training and including hamstring curls, wall squats, and gait training. Weeks 4-8: resistance exercises were carried out for 50 min at least 5 times per week focusing on the hip abductor, hip adductor, the quadriceps, hamstrings, and calf muscles. (b) postoperative week 1 for NT group: Ankle pumps and proprioception exercises were performed for $30 \mathrm{~min}, 7$ days per week from a fixed position with eyes closed, such as straight leg raised in the supine position or leg bent in the seated position. Weeks $2-4$ : subjects were given sit-up exercises that required lying on a bobath ball with the knees bent to stabilize the ball, hips-up exercises with the subject lying on the bobath ball and the knees bent to stabilize the ball while performing hips-up movements with both knees in a fixed position; forward lunges in which the subject stood straight, lunged forward, an incomplete circle that require the subject to stand on one leg and use the other leg to draw a semicircle, toe target movements, and knee touch movements. Other exercises included standing and static balancing training, training on a balancing board, ball catching in the squat position, and step training for at least 50 min per day, a minimum of 5 days per week. Weeks 4-8: Subjects were given training exercises for 50 min for at least 5 days per week focusing on balance and walking abilities, flexibility, and dynamic stability of the knee.

\section{Assessment}

Rehabilitation assessments, such as the Lysholm knee scoring (LKS) was employed to test knee function before surgery and 
again at 4 and 8 weeks following the meniscectomy procedure. Functional performance tests (FPTs) included a 30-sec one-leg raise test and a square-hop test. In the 30-sec one-leg raise test, the subject sat on a chair of $45 \mathrm{~cm}$ in height, stood up with the leg straight, and sat back down in the chair immediately when instructed. This process was repeated for $30 \mathrm{sec}$. The healthy leg was tested first followed by the injured leg. The arms and the body were not allowed to swing during the duration of the test and the number of times the subject stood or sat during the 30-sec test was recorded as previously reported (Hall et al., 2015). For the square-hop test evaluation, the subject was asked to stand in front of a $30 \mathrm{~cm} \times 35 \mathrm{~cm}$ square and was instructed to hop into different zones, beginning at zone 0 , in a clockwise sequence while hearing the following commands: zone $1 \rightarrow$ zone $2 \rightarrow$ back to zone $0 \rightarrow$ zone

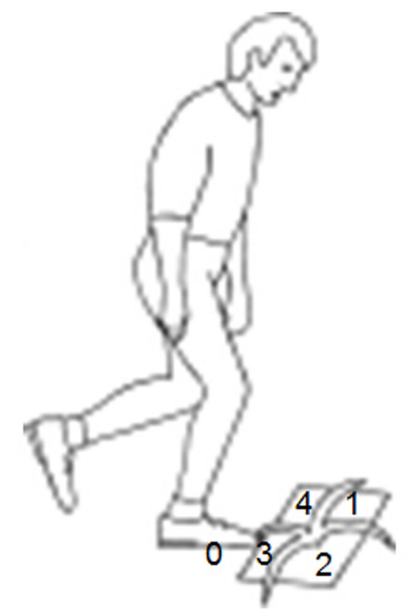

Fig. 1. Illustration of the directions in the square-hop test.

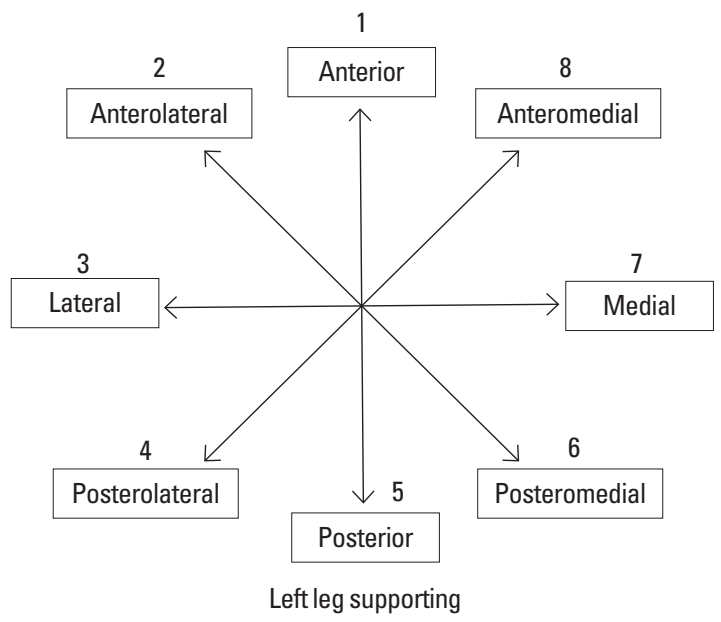

$3 \rightarrow$ zone 4, as shown in Fig. 1. The healthy leg was tested first followed by the injured leg. The number of valid motions, excluding jumps with both legs, hops in a wrong direction, and hops stepping on the border marks, within a 10-sec period was recorded as previously described (Bremander et al., 2007; Ericsson et al., 2006). The third test used was the star excursion balance test (SEBT), which has been described in detailed elsewhere (Chaiwanichsiri et al., 2005; Gribble and Hertel, 2003). In brief, the SEBT method first requires to measure the length of the subjects' legs in the prone position. The subject is then allowed to carry out the test in eight directions as follows: anterior, anterolateral, lateral, posterolateral, posterior, posteromedial, medial, and anteromedial. During the test, the subjects were told to place their hands on their hips, stand on one leg in the center of an 8-point star while bending the supporting leg, and extending the other leg as far as possible towards the eight directions at every $45^{\circ}$ angle (Fig. 2). The subjects carried out the tests in a counter-clockwise manner when using the left leg as support and in the clockwise direction when using the right leg as support. As shown in Fig. 2, the subject proceeded from point 1 to point 8 on each leg. Before moving to the next direction, the subject was required to return the extended leg back to the central position and stand on both legs to rest for $3 \mathrm{sec}$ in order to prevent discrepancies in the test results due to improper body balance. The test was repeated 5 times and the average value of the top three results was calculated. When moving in the lateral and posterolateral directions, the subject was required to swing the leg being tested back to the supporting leg to complete the action as described previously. The fourth test applied was the isokinetic muscle strength assessment of the sub-

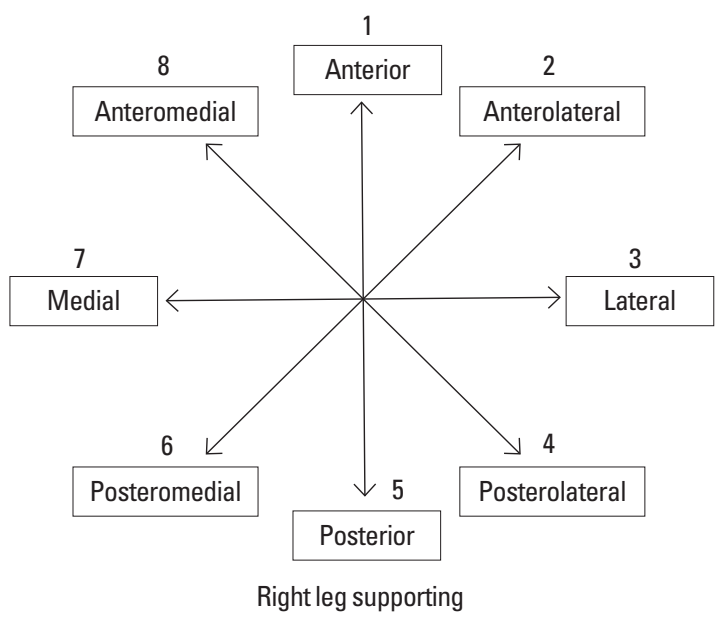

Fig. 2. Illustration of the directions in the star excursion balance test. 
ject's knee extensors and flexors. For this we used the PrimusRS (BTE, Greenwood Village, CO, USA) physical therapy equipment specifically designed for multijoint isokinetic testing according to previously described methods, which was routinely calibrated prior to each test (Bonfim et al., 2003). In brief, the subjects were allowed to warm up on a cycle ergometer for 5 min before starting the test. The subject was then asked to sit on a seat placed at a $90^{\circ}$ angle during the entirety of the test. The axis of the knee was placed in line with the axis of the power arm and the resistance pad with the rear of the power arm fixed $3 \mathrm{~cm}$ above the medial malleolus of the ankle. This allowed a motion range of the joint between $15^{\circ}$ and $100^{\circ}$. The test was performed at two angular velocities of a $60^{\circ} / \mathrm{sec}$ and $120 \% \mathrm{sec}$ respectively. The subject performed 3 maximal contractions at these 2 angular velocities with a 60-sec rest between each contraction. Prior to the formal test at each velocity, the subject performed 3 sets of submaximal flexion-extension exercises as a warm-up. The subject's healthy leg was tested first followed by the injured leg 2 min later. The $R$ value was calculated as the ratio of the peak torque (PT) of the same muscle group between both knees (healthy leg/injured leg). The $R$ value indicated an optimal recovery of maximal muscle strength and endurance when it lied close to 1 . The flexors/extensors torque ratios $(\mathrm{F} / \mathrm{E})$ on either knee were also calculated and used as a balance indicator and motion control ability.

\section{Statistical analysis}

Data were expressed as mean \pm standard error and analyzed using SPSS ver. 17.0 (SPSS Inc., Chicago, IL, USA). LKS and BTE PrimusRS isokinetic test results were compared by two-way analysis of variance. The SEBT results were analyzed using multifactor variance analysis and the FPT results were analyzed using a chi-square test. Differences were considered statistically significant when $P<0.05$.

\section{RESULTS}

\section{Lysholm knee scoring}

The assessment of knee function in the LKS test taken preopera-

Table 2. Lysholm knee scores $(n=15)$

\begin{tabular}{lcc}
\hline Time & ST group & NT group \\
\hline Preoperation & $60.2 \pm 2.79$ & $61.2 \pm 2.35$ \\
4-Week postoperation & $87.8 \pm 5.34^{\dagger}$ & $88.1 \pm 3.45^{\dagger}$ \\
8-Week postoperation & $94.8 \pm 5.45^{*, \dagger}$ & $90.9 \pm 2.78^{\dagger}$ \\
\hline
\end{tabular}

Values are presented as mean \pm standard error.

ST, strength training; NT, neuromuscular training.

* Intergroup comparison, $P<0.05$. Intragroup comparison, $P<0.01$. tive from the two groups were comparable and without significant differences (Table 2) $(P>0.05)$. After 4 and 8 weeks of rehabilitation, the LKS scores improved significantly within both groups $(P<0.05)$. At 8 weeks post operation, the LKS in the ST group was significantly higher than that in the NT group $(P<0.05)$.

\section{Functional performance tests}

Both NT and ST groups performed significantly better on the injured leg in the 30-sec one-leg raise test and square-hop test as compared with their preoperative performance (Table 3$)(P<0.01)$. After 8 weeks of training, the athletes in the ST group performed better in the 30-sec one-leg raise test than the athletes placed in the NT group $(P<0.05)$. However, the athletes in the NT group scored significantly higher in the square-hop test than the athletes in the ST group $(P<0.05)$. The NT and ST group differences were found to be statistically significant $(P<0.01)$.

\section{Standardized SEBT}

Both the NT and ST group performance were significantly improved in all the 8 directions taken in the plyometric after training (Table 4) $(P<0.01)$. Moreover, the SEBT scores in the NT group were significantly higher than those in the ST group $(P<0.01)$.

\section{BTE PrimusRS isokinetic performance test}

The $R$ value and the $\mathrm{F} / \mathrm{E}$ ratio of the BTE PrimusRS isokinetic test at $60 \%$ sec and $120^{\circ} / \mathrm{sec}$ were significantly increased in both groups after eight weeks of training (Table 5$)(P<0.01)$. The $R$ value of the extensor at $60^{\circ} / \mathrm{sec}$ was significantly higher in the ST group than that in the NT group $(P<0.05)$. After 8 weeks of training, the $R$ value of the flexor at $120^{\circ} / \mathrm{sec}$ and the $\mathrm{F} / \mathrm{E}$ ratio of the injured leg were significantly increased in the NT group compared to the $R$ value from the ST group $(P<0.05)$.

Table 3. Functional performance tests $(n=15)$

\begin{tabular}{|c|c|c|c|c|}
\hline \multirow[b]{2}{*}{ Group } & \multicolumn{2}{|c|}{ 30-Sec one-leg rise test } & \multicolumn{2}{|c|}{ Square-hop test } \\
\hline & Preoperation & $\begin{array}{c}\text { 8-Week } \\
\text { posttraining }\end{array}$ & Preoperation & $\begin{array}{c}\text { 8-Week } \\
\text { posttraining }\end{array}$ \\
\hline \multicolumn{5}{|l|}{ ST } \\
\hline $\mathrm{H}$ & $15.8 \pm 6.0$ & $15.7 \pm 7.0$ & $6.0 \pm 3.0$ & $7.0 \pm 1.0$ \\
\hline I & $10.5 \pm 7.0$ & $14.3 \pm 7.0^{*, \dagger}$ & $4.0 \pm 3.0$ & $6.0 \pm 3.0^{\dagger}$ \\
\hline \multicolumn{5}{|l|}{ NT } \\
\hline H & $15.8 \pm 7.0$ & $16.2 \pm 7.0$ & $6.0 \pm 4.0$ & $7.0 \pm 5.0$ \\
\hline । & $10.4 \pm 6.0$ & $12.2 \pm 6.0^{\dagger}$ & $4.0 \pm 4.0$ & $8.0 \pm 4.0^{*, \dagger}$ \\
\hline
\end{tabular}

Values are presented as mean \pm standard error.

ST, strength training; NT, neuromuscular training.

${ }^{*}$ Intergroup comparison, $P<0.05$. ${ }^{~ I n t r a g r o u p ~ c o m p a r i s o n, ~} P<0.01$. 
Table 4. Standardized star excursion balance test results before and after training $(n=15)$

\begin{tabular}{|c|c|c|c|c|c|}
\hline \multirow{2}{*}{ Direction } & \multirow{2}{*}{ Group } & \multicolumn{2}{|c|}{ Left leg supporting } & \multicolumn{2}{|c|}{ Right leg supporting } \\
\hline & & Pretraining & Posttraining & Pretraining & Posttraining \\
\hline \multirow[t]{2}{*}{ ANT } & ST & $67.17 \pm 4.87$ & $68.06 \pm 6.24$ & $66.48 \pm 7.75$ & $67.01 \pm 6.34$ \\
\hline & NT & $67.35 \pm 7.26$ & $85.18 \pm 6.35^{*, \dagger}$ & $67.18 \pm 6.48$ & $85.30 \pm 5.32^{*, t}$ \\
\hline \multirow[t]{2}{*}{ ALAT } & ST & $62.66 \pm 8.16$ & $62.78 \pm 6.64$ & $65.08 \pm 4.35$ & $65.15 \pm 3.11$ \\
\hline & NT & $63.62 \pm 7.37$ & $83.28 \pm 6.61^{*, \dagger}$ & $65.38 \pm 4.74$ & $86.15 \pm 3.56^{*,+}$ \\
\hline \multirow[t]{2}{*}{ LAT } & ST & $55.76 \pm 6.62$ & $56.33 \pm 5.48$ & $56.13 \pm 6.12$ & $57.03 \pm 7.54$ \\
\hline & NT & $56.02 \pm 7.11$ & $76.51 \pm 6.36^{*, t}$ & $55.82 \pm 4.52$ & $76.13 \pm 8.52^{*, t}$ \\
\hline \multirow[t]{2}{*}{ PLAT } & ST & $68.71 \pm 4.70$ & $69.53 \pm 3.71$ & $69.93 \pm 4.76$ & $70.18 \pm 3.51$ \\
\hline & NT & $69.09 \pm 5.43$ & $85.16 \pm 4.59^{*, t}$ & $70.06 \pm 3.72$ & $88.53 \pm 3.56^{*,+}$ \\
\hline \multirow[t]{2}{*}{ POST } & ST & $80.16 \pm 5.28$ & $81.13 \pm 3.36$ & $79.41 \pm 3.73$ & $78.92 \pm 3.85$ \\
\hline & NT & $79.92 \pm 6.68$ & $87.29 \pm 6.46^{*, \dagger}$ & $79.37 \pm 4.76$ & $90.37 \pm 4.76^{*,+}$ \\
\hline \multirow[t]{2}{*}{ PMED } & ST & $70.31 \pm 4.29$ & $71.42 \pm 3.25$ & $71.41 \pm 3.82$ & $71.63 \pm 4.86$ \\
\hline & NT & $69.98 \pm 5.13$ & $92.89 \pm 7.21^{*,+}$ & $71.09 \pm 5.12$ & $90.28 \pm 5.45^{*,+}$ \\
\hline \multirow[t]{2}{*}{ MED } & ST & $68.03 \pm 5.51$ & $68.75 \pm 6.21$ & $68.82 \pm 6.42$ & $69.26 \pm 7.11$ \\
\hline & NT & $68.62 \pm 6.65$ & $87.82 \pm 7.32^{*,+}$ & $68.91 \pm 6.92$ & $69.01 \pm 7.92$ \\
\hline \multirow[t]{2}{*}{ AMED } & ST & $69.29 \pm 6.45$ & $69.18 \pm 6.82$ & $70.33 \pm 4.12$ & $70.48 \pm 5.08$ \\
\hline & NT & $69.46 \pm 6.51$ & $89.71 \pm 8.26^{*, \dagger}$ & $69.95 \pm 5.37$ & $89.56 \pm 7.75^{*, t}$ \\
\hline
\end{tabular}

Values are presented as mean \pm standard error.

ANT, anterior; ALAT, anterolateral; LAT, lateral; PLAT, posterolateral; POST, posterior; PMED, posteromedial; MED, medial; AMED, anteromedial; ST, strength training; NT, neuromuscular training.

${ }^{*}$ Comparison between pre- and posttraining results within the group, $P<0.05 .{ }^{~}$ Comparison of posttraining results between the two groups, $P<0.01$.

Table 5. Pre- and posttraining $R$ value and $\mathrm{F} / \mathrm{E}$ ratio in the isokinetic test at $60^{\circ} / \mathrm{sec}$ and $120 \% \mathrm{sec}(\mathrm{n}=15)$

\begin{tabular}{|c|c|c|c|c|c|}
\hline \multirow{2}{*}{$R$ value \& F/E ratio } & \multirow{2}{*}{ Group } & \multicolumn{2}{|c|}{$60^{\circ} / \mathrm{sec}$} & \multicolumn{2}{|c|}{$120 \% / \mathrm{sec}$} \\
\hline & & Preoperation & 8-Week posttraining & Preoperation & 8-Week posttraining \\
\hline \multirow[t]{2}{*}{ Extensor $R$} & ST & $0.46 \pm 0.05$ & $0.86 \pm 0.05^{*, \dagger}$ & $0.44 \pm 0.07$ & $0.86 \pm 0.01^{*}$ \\
\hline & NT & $0.46 \pm 0.06$ & $0.83 \pm 0.03^{*}$ & $0.45 \pm 0.01$ & $0.88 \pm 0.02^{*}$ \\
\hline \multirow[t]{2}{*}{ Flexor $R$} & ST & $0.41 \pm 0.02$ & $0.80 \pm 0.04^{*}$ & $0.40 \pm 0.02$ & $0.80 \pm 0.03^{*}$ \\
\hline & NT & $0.40 \pm 0.03$ & $0.81 \pm 0.03^{*}$ & $0.40 \pm 0.05$ & $0.85 \pm 0.06^{*, t}$ \\
\hline \multirow[t]{2}{*}{ F/E healthy } & ST & $0.58 \pm 0.01$ & $0.60 \pm 0.02$ & $0.60 \pm 0.03$ & $0.61 \pm 0.05$ \\
\hline & NT & $0.59 \pm 0.02$ & $0.61 \pm 0.01$ & $0.61 \pm 0.12$ & $0.62 \pm 0.06$ \\
\hline \multirow[t]{2}{*}{ F/E injured } & ST & $0.56 \pm 0.03$ & $0.60 \pm 0.04^{*}$ & $0.58 \pm 0.04$ & $0.61 \pm 0.01^{*}$ \\
\hline & NT & $0.57 \pm 0.01$ & $0.63 \pm 0.02^{*,+}$ & $0.57 \pm 0.05$ & $0.64 \pm 0.04^{*, t}$ \\
\hline
\end{tabular}

Values are presented as mean \pm standard error.

${ }^{*}$ Comparison between pre- and posttraining results within the group $P<0.01$. ${ }^{\dagger}$ Intergroup comparison, $P<0.05$.

\section{DISCUSSION}

To evaluate the effect of early rehabilitation on knee joint function of athletes subjected to arthroscopic partial medial meniscectomy, a subjective function assessment was developed to reflect the strength of the skeletal muscles and the total functional performance of the knee joint. In this study, meniscal tear symptoms were significantly improved in patients undergoing strength (ST) and NT after 4 and 8 weeks of training. The LKS scores were not significantly different between the NT and ST groups after 4 weeks. However, after 8 weeks, the LKS in the ST group was significantly higher than that in the NT group. Several athletes experienced joint swelling and pain after the NT program, which was probably due to the lateral and rotational forces applied to the knee joint.

In order to fully examine the functional performance of the athletes evaluated here, FPTs were assessed as previously reported (Bremander et al., 2007; Ericsson et al., 2006). The results of the 30-sec one-leg raise test showed that athletes' performance in both groups was markedly improved after intense rehabilitation train- 
ing. Since ST programs mainly employ isometric and isotonic exercises to improve muscle strength, ST can also effectively improve the strength of target muscles. Therefore, the athletes belonging to the ST group performed better in strength testing than those in the NT group. Both training groups remarkably improved the dynamic balance, coordination, and strength, of the legs compared with the tests performed in the preoperative phase. Since NT programs include balance enhanced training, knee dynamic stability, proprioception sensing, and agility exercises, the athletes in the NT group obtained a better test performance than the ST group thanks to the balance and coordination exercise included in the NT regime, while the strength of the leg muscles was improved in both ST and NT programs thanks to the strength exercises included in both trainings. There results suggested that the NT program is a more complete and appropriated training after arthroscopic partial medial meniscectomy, improving the strength, dynamic balance, and coordination of the leg muscles.

The SEBT is a reliable measurement with a relatively high degree of sensitivity, especially in monitoring sports-injury related functional defects in the legs (Gray, 1995; Hale et al., 2007; O'Driscoll et al., 2011). In the current study, the athletes subjected to the NT group performed better on both legs in all the 8 directions tested compared to those in the ST group, in which no significant improvement was observed after robust training. These results suggests that lower limbs can achieve a relatively higher balance degree after NT compared with ST due to better focused exercises included in the NT program that involve balance enhanced training, knee dynamic stability, proprioception, and agility exercises as described above, while ST program mostly involved exercises dedicated to improve muscle strength and not muscle balance.

Isokinetic muscle testing of the knee is an important assessment index, since a relative balance in the extensor and flexor strength of the knee joint is an objective of postinjury rehabilitation and reinjury prevention (Sole et al., 2007). An ideal F/E ratio ranges from $50 \%$ to $80 \%$. The F/E ratio of a young male's healthy knee in an isokinetic test at an angular velocity of $60 \% \mathrm{sec}$ is $51.9 \%$ $53.1 \%$, and the $\mathrm{F} / \mathrm{E}$ ratio of a good athlete is greater than that of an ordinary man. Muscle strength recovery is one of the main goals of rehabilitation. Generally, the difference in muscle strength in an individual's legs ranges between $10 \%$ and $15 \%$, and it is not greatly affected by different test velocities. A $20 \%$ difference in the muscle strength between the legs indicates a muscle strength myodynamic imbalance or a poor recovery after rehabilitation. Recovery of muscular endurance is another key aspect that is often ignored in rehabilitation training. Practical evidence indicates that premature fatigue in skeletal muscles is a direct result of poor recovery of muscular endurance and it is one of the main reasons for compromised dynamic balance control and postoperative reinjury.

In this study, the extensor and flexor $R$ values and the $\mathrm{F} / \mathrm{E}$ ratios of the injured knees were significantly improved after 8 weeks of training, suggesting that both rehabilitation plans resulted in an improvement in muscles strength, endurance, and balance after partial medial meniscectomy. Furthermore, the results of the isokinetic test demonstrated that both NT and ST rehabilitation plans could increase the strength of the skeletal muscles. Indeed, while ST programs mainly employ isometric and isotonic exercises to improve muscle strength, NT programs include stretch-contraction cycles (plyometric), jumping exercises, and stretch-shortening cycles. In addition, NT programs include balance enhanced training, knee dynamic stability, proprioception, and agility exercises. This type of progressive training can stimulate stretch-contraction and enhance the improvement in muscular strength, which may explain the greater muscle strength balance observed in the NT group in the fast motion test.

In conclusion, both the strength and NT groups of athletes achieved an effective recovery after 8 weeks of rehabilitation training. However, even though a progressive and effective improvement in target muscle strength was observed following ST programs, NT programs not only increased muscular strength, but also improved dynamic balance and coordination greatly improving knee joint recovery after arthroscopic partial medial meniscectomy. Of note, the 8 weeks is not a long enough period of time for a full recovery after meniscectomy and these athletes must be continuously reassessed in the following months after surgery.

\section{CONFLICT OF INTEREST}

No potential conflict of interest relevant to this article was reported.

\section{ACKNOWLEDGMENTS}

This trial is being funded by Science and Technology Planning Project of Guangdong Province, China (program grant: 2014A02 0220011).

\section{REFERENCES}

Ageberg E, Link A, Roos EM. Feasibility of neuromuscular training in patients with severe hip or knee OA: the individualized goal-based NE- 
MEX-TJR training program. BMC Musculoskelet Disord 2010;11:126.

Bennell KL, Egerton T, Wrigley TV, Hodges PW, Hunt M, Roos EM, Kyriakides M, Metcalf B, Forbes A, Ageberg E, Hinman RS. Comparison of neuromuscular and quadriceps strengthening exercise in the treatment of varus malaligned knees with medial knee osteoarthritis: a randomised controlled trial protocol. BMC Musculoskelet Disord 2011;12:276

Bonfim TR, Jansen Paccola CA, Barela JA. Proprioceptive and behavior impairments in individuals with anterior cruciate ligament reconstructed knees. Arch Phys Med Rehabil 2003;84:1217-1223.

Bremander AB, Dahl LL, Roos EM. Validity and reliability of functional performance tests in meniscectomized patients with or without knee osteoarthritis. Scand J Med Sci Sports 2007;17:120-127.

Brindle T, Nyland J, Johnson DL. The meniscus: review of basic principles with application to surgery and rehabilitation. J Athl Train 2001;36: 160-169.

Chaiwanichsiri D, Lorprayoon E, Noomanoch L. Star excursion balance training: effects on ankle functional stability after ankle sprain. J Med Assoc Thai 2005;88 Suppl 4:S90-94.

Ericsson $\mathrm{YB}$, Dahlberg LE, Roos EM. Effects of functional exercise training on performance and muscle strength after meniscectomy: a randomized trial. Scand J Med Sci Sports 2009;19:156-165.

Ericsson YB, Roos EM, Dahlberg L. Muscle strength, functional performance, and self-reported outcomes four years after arthroscopic partial meniscectomy in middle-aged patients. Arthritis Rheum 2006;55: 946-952.

Goodwin PC, Morrissey MC. Physical therapy after arthroscopic partial meniscectomy: is it effective? Exerc Sport Sci Rev 2003;31:85-90.

Gray GW. Lower extremity functional profile. Adrian (MI): Wynn Marketing Inc.; 1995.

Gribble PA, Hertel J. Considerations for normalizing measures of the star excursion balance test. Meas Phys Educ Exerc Sci 2003;7:89-100.

Griffin LY, Agel J, Albohm MJ, Arendt EA, Dick RW, Garrett WE, Garrick JG, Hewett TE, Huston L, Ireland ML, Johnson RJ, Kibler WB, Lephart S, Lewis JL, Lindenfeld TN, Mandelbaum BR, Marchak P, Teitz CC, Wojtys EM. Noncontact anterior cruciate ligament injuries: risk factors and prevention strategies. J Am Acad Orthop Surg 2000;8:141-150.

Hale SA, Hertel J, Olmsted-Kramer LC. The effect of a 4-week comprehensive rehabilitation program on postural control and lower extrem- ity function in individuals with chronic ankle instability. J Orthop Sports Phys Ther 2007;37:303-311.

Hall M, Hinman RS, Wrigley TV, Roos EM, Hodges PW, Staples MP, Bennell KL. Neuromuscular exercise post partial medial meniscectomy: randomized controlled trial. Med Sci Sports Exerc 2015;47:15571566.

Hübscher M, Zech A, Pfeifer K, Hänsel F, Vogt L, Banzer W. Neuromuscular training for sports injury prevention: a systematic review. Med Sci Sports Exerc 2010;42:413-421.

Hunt MA, Birmingham TB, Giffin JR, Jenkyn TR. Associations among knee adduction moment, frontal plane ground reaction force, and lever arm during walking in patients with knee osteoarthritis. J Biomech 2006;39:2213-2220.

Koutras G, Letsi M, Papadopoulos P, Gigis I, Pappas E. A randomized trial of isokinetic versus isotonic rehabilitation program after arthroscopic meniscectomy. Int J Sports Phys Ther 2012;7:31-38.

Matthews P, St-Pierre DM. Recovery of muscle strength following arthroscopic meniscectomy. J Orthop Sports Phys Ther 1996;23:18-26.

O'Driscoll J, Kerin F, Delahunt E. Effect of a 6-week dynamic neuromuscular training programme on ankle joint function: a case report. Sports Med Arthrosc Rehabil Ther Technol 2011;3:13.

Ortiz A, Olson SL, Etnyre B, Trudelle-Jackson EE, Bartlett W, Venegas-Rios HL. Fatigue effects on knee joint stability during two jump tasks in women. J Strength Cond Res 2010;24:1019-1027.

Roos EM, Dahlberg L. Positive effects of moderate exercise on glycosaminoglycan content in knee cartilage: a four-month, randomized, controlled trial in patients at risk of osteoarthritis. Arthritis Rheum 2005; 52:3507-3514.

Sole G, Hamrén J, Milosavljevic S, Nicholson H, Sullivan SJ. Test-retest reliability of isokinetic knee extension and flexion. Arch Phys Med Rehabil 2007;88:626-631.

Thorstensson CA, Henriksson M, von Porat A, Sjödahl C, Roos EM. The effect of eight weeks of exercise on knee adduction moment in early knee osteoarthritis: a pilot study. Osteoarthritis Cartilage 2007;15:11631170.

Zech A, Hübscher M, Vogt L, Banzer W, Hänsel F, Pfeifer K. Neuromuscular training for rehabilitation of sports injuries: a systematic review. Med Sci Sports Exerc 2009;41:1831-1841. 